as it does when shaken up in alkaline solution, with oxygen or air. In this way it is changed into biliverdin. Now, re-entering the liver, it comes in relation with the glycogen and yields up to it its water, becom. ing reconverted into bilirubin and reconverting gly. cogen into glucose. The atom of oxygen associated with the molecule of water, and liberated with it, is no doubt applied to the final oxidation of nitrogenous bodies which have served their ends in the economy. Of this reaction the urea formed in the liver is the product. The liver may be regarded as a chemicovital laboratory in which certain elements of the food are prepared for assimilation; while others which have yielded up their capacity for meeting the demands of structure and function are prepared for elimination. The coloring matter serves the livercells in effecting these transformations by acting as a carrier of water and oxygen.

All honor to the men who are devoting themselves to arduous experimental work. Yet it is as much legitimate seientific progress to deduce the meaning of a fact as it is to get the fact. It is believed that the view presented in this paper is logical, consistent and true, resting upon a basis of accepted science. $A s$ an interpretation, then, of facts reached-to be sure, through the labors of others-it is hoped that it presents claims worthy of consideration.

Discussion.

Dr. PEAvY - In closing this discussion $I$ have nothing to add directly to the material contained in the paper itself. I am glad that Dr. Van Zandt has referred to the fact that hitherto no satisfactory explanation has been proposed of the mechan ism by which the chlorophyl-bearing cells of plants decompose carbon dioxid and water, nor of the rationale of the oxygen. carrying and distributing function of the red-blood cells. These very difficulties first led to the investigations which re sulted in the development of the view here presented. That the solutions offered are the true ones, my own mind no longer entertains a doubt.

In the decompositions effected by light in the green leaves of plants we have no more disturbance of unstable chemic balances, but the dissolution by a definite mechanism of the firmest chemic bonds. That the energy expended in effecting these decompositions is derived from the sun's rays, and is represented in the attraction of the divorced atoms for each other, is entirely beyond question. The process is clearly a conversion of mechanical into chemic energy. The postulate that this conversion and electro-chemic decomposition are ac. complished through magnetization of the iron contained in the vegetal cells appears not only fully warranted by the premises adduced in the body of the paper, but it seems to be the only possible mechanism of the process. The facts of electrolytic decomposition and of the magneto-electric conversion of energy appear of themselves sufficient to render the conclu sion necessary.

The theory that the oxygen carrying and distributing capac ity of hemoglobin is dependent upon a property of its iron, allowing it to exercise either positive or negative affinities un der different conditions, appears also to satisfy the logical demands of the problem, and be fully justified by the facts of physics, chemistry and physiology. In proposing this explanation we are assuming no new property for iron. That it does manifest sometimes acid and sometimes basic proclivities is a well established fact. Its behavior in this regard is deter mined by its chemic environment.

Manganese, so closely related to iron in the electro chemic position and properties, shares with it this oxygen-carrying function in the blood. The so called catalytic action of black oxid of manganese, as illustrated in laboratory experiments, but shows the capacity of this substance under molecular agitation-heat-to take on and give off oxygen. Indeed, in certain chemic reactions manganese salts play the part of intermediary bodies, acting as carriers of oxygen, taking it from one and giving it to another of two bodies without being them selves directly affected in the reaction.

Blood outside the body, as long as it retains its vitality, will turn purple if oxygen be excluded, and then red again if oxy gen be supplied. This shows that even without the special conditions furnished in the circulating blood, hemoglobin, the color of which depends upon its degree of oxygenation, tends spontaneously to take on oxygen, liberate it and renew its supply. As far as this part of our theory is concerned, the proof amounts to scarcely less than practical demonstration.

Dr. Van Zant might have added that physiologists have never hitherto furnished the bile with a function in keeping with the quantity and constancy of this secretion. Doubtless it performs some secondary part in intestinal digestion- the green bile formed during the progress of digestion and absorption taking part, it may be in the hydrations and oxidations going on in the alimentary canal at that time. Intestinal digestion, however, is fairly well performed without the presence of bile, so we conclude that it is not primarily a digestive secretion. That it is not an excrementitious product is evident from its reabsorption from the intestine during the intervals of digestion. If the bile flow of the dog be diverted from the alimentary canal and discharged externally through a fistula, it is found that, while the appetite remains good and digestion is well performed, the animal soon begins to waste and finally dies from disordered nutrition. A significant fact is that the bile flow itself rapidly diminishes in quantity and becomes very scant. From this experiment we conclude that the bile is essential in some way to the nutrition of the body, and that its partial reabsorption is necessary to furnish part of the materials for continued secretion. So we seem forced to the conclusion that bile performs its most important function in the liver itself, and that even after it reaches the intestine in the intervals of digestion, it has not yet consummated its work. Whether the task I laid for it will meet with approval of physiologists generally remains to be seen. I wish to disclaim any intention of arrogating to the coloring matter the whole function of the bile. Only such part of it as is specially fitted by nature to perform and which is in general line with the work of this class of physiologic agents do I claim for its own specific function.

\section{METHOD OF TEACHING MATERIA MEDICA.}

\section{WITH SPECIAL REFERENCE TO DENTAL STUDENTS.}

Presented to the Section on Stomatology, at the Forty-ninth Annual Meeting of the American Medical Aseociation, held at Denver, Colo., June 7-10, 1898.

BY WARREN B. HILL, M.D.

PROFESSOR Ó MATERIA MEDICA AND THERAPEUTICs, MILWACKEE MEDTCAL COLLEGE.

$$
\text { MILWACKEE, WIS. }
$$

This subject, like many others, has two aspects: the real and the ideal. Dentistry is in a transition period. Some years ago it was almost a mechanical art, but there have always been in the profession men who held high ideals, and through their earnestness, enthusiasm and work it is being rapidly transformed into an ideal profession. In its highest sense dentistry should be, and is, a specialism in medicine, and the work of a number of men in this country has demonstrated that the best results and greatest achievements may be derived by making it so.

There is a tendency in the civilized world toward specialization. It has been found that higher attainments can thus be reached. But on the other hand, through narrowing the field of work, we are apt to contract the mind, and thus we find that which we gain in skill compensated by a loss in broader comprehension. It becomes necessary, therefore, when training a mind for specialty work, that we have a broad foundation upon which to build. It is not sufficient that one entering the study of dentistry should have acquired a certain amount of knowledge of English, mathematics and physics, but his mind should have been trained in broader fields, so that the concentration upon this single study will not have the effect of dwarfing the intellect and narrowing the mind.

The fundamentals of medicine should have been mastered early in his dental study, and his mind have been trained in grappling with the more abstruse problems in medicine, before he is obliged to concen- 
trate his entire attention upon a portion of the oral cavity. I believe this proposition to be true from the standpoint of an educator, whose business it is to build up and round off a symmetric mind and character, and I believe it is also true from the standpoint of the practitioner, who, to be successful, must be familiar with all the factors that bear more or less remotely upon the conditions which he is treating. Thus, if we could teach dentistry according to this ideal, the question, "How much materia medica shall we teach?" would be answered thus: "All that is taught in the study of medicine." However, the obstacles that present themselves are a lack of time in the curriculum and a lack of disposition on the part of the student.

In a three-year course of six or seven months each year the average dental student is overworked in mastering the fundamentals of dentistry and medicine, and in doing the amount of laboratory and infirmary work necessary to make him proficient. It has become necessary, therefore, to abridge the work in materia medica, as well as in anatomy and physiology, in order that they may have sufficient time for the dental laboratory. In our institution there are some who are better endowed by nature, and who have a higher ambition than the average student. Realizing the advantages that present themselves by attending a school where both medicine and dentistry are taught, they are taking the full course in materia medica, therapeutics, anatomy, etc., thus completing, in a large measure, the fundamental work in medicine, in the anticipation of earning a medical degree, as well as that of D.D.S., in order that they may be better equipped for their practice, and at the same time they are rounding out their education and giving their minds a broader development.

For the average student the number of remedies in materia medica must necessarily be limited. The escharotics, the antiseptics and those that are used particularly in their everyday practice must have pre. cedence, but there are many others whose actions have a remote influence upon the mouth and its diseases, which must also be taught. All of those affecting nutrition and assimilation have a direct interest to the dentist, and the art of prescribing should not be neglected, as it sometimes is. Having selected the few remedies we wish to teach, what to teach about them should be our next concern. All that we know is hardly too much. Their pharmacology is essential, their constituents and chemistry should be taught, and their physiologic action in its broadest sense should not be neglected, and then their therapeutic value in dentistry, as well as in medicine, should be the cap-sheaf of our investigation.

The question of how we shall teach it is a much more difficult one. Teachers are born, not made, and each teacher must adopt a method adapted to himself. In my work I have found the pharmacology of a drug can best be taught by object-lesson. The laboratory may be provided or improvised; it is only necessary that the student shall have an actual living acquaintance with the drug. The physiologic and therapeutic action can best be taught by didactic lectures, wherein the student may partake of the enthusiasm of his teacher, and may be made to feel, through that enthusiasm, the effects on long and personal experience with the remedy, which will inspire him with confidence-a mighty adjuvant in the application of drugs. There is much, however, that should be eliminated from our lectures. The names, preparations, composition, chemic reaction, doses, etc., should be supplied in advance, that the student may commit them to mem. ory, and have regular recitations and drill on them. This work should precede, or go hand in hand with, the laboratory work. I have never found a text-book which taught just what I wished to teach of any particular drug, nor one which treated only of those drugs which I esteemed of greatest importance to the student. I, therefore, have adopted a system of preparing skeleton notes which embrace those things that the student must commit to memory, furnishing mimeograph copies to each of the students, and leave for my didactic lectures that which I feel I could enliven by my personality. I have followed this course for three years, and the increased proficiency of the classes since its adoption has demonstrated to me the efficacy of the plan.

Having familiarized himself with the pharmacology of a drug, the student now comes to the most interesting part of his study. He has been grounded in his physiology, his chemistry, and his pathology, and now he is enabled to see the practical applicability of this knowledge in the application of the remedies to diseases. After due consideration, I have omitted to place upon my skeleton notes anything of the physiologic action or therapeutics of a drug, because they are not to be memorized, but to be reasoned out. Just how a drug acts primarily upon one organ, and through some of the great systems of the body results in a secondary action upon another organ, and drawing the parallelisms between the action of remedies and the pathologic conditions in diseases is as fascinating a study to the student in medicine or dentistry as is the illustrating of a natural law in physics. This is the logic of medicine.

In teaching therapeutics it is not sufficient to tell what diseases may be cured, and which harmed by the administration of a given drug. It makes a fascinating study for a student to take a disease, hunt out its etiology, trace the pathologic changes that take place, for the purpose of selecting a remedy that will overcome the conditions known to be present, eradicate the etiologic factor, or to build up certain structures in order to offset the destructive processes of the disease.

In my work this is still further supplemented by a course of applied therapeutics, in which we have the patient before us. We now can no longer follow the classic lines laid down in books, but must take diseases as find them, modified by the various agencies that environ the human animal. The pathologic conditions must here be studied out and remedies found that will logically supply the indications. If, perchance, in this course the student has witnessed diseases treated which are of little interest to him as far as he is concerned in his practice, he may have been given a lesson in mind culture that will serve him in good stead. The power of reasoning from effect to cause, and back to effect, is the best mental discipline for cultivating practical minds.

Potion for Whooping=Cough (L. Concetti).-Resorcin 2 gm. ; antipyrin $1 \mathrm{gm}$.; aq. dest. $70 \mathrm{gm}$. ; syrup of codein $10 \mathrm{gm}$. ; syrup of cedar $20 \mathrm{gm}$. ; tincture of opium 3 drops ; tincture of belladonna 8 drops. A teaspoonful every hour or second hour to infants; a dessert.spoonful for children from one to three; and a tablespoonful for children over three.-Semaine Méd., No. vember 30 . 